\title{
A review of recent publication trends from top publishing countries
}

\author{
Paul Fontelo ${ }^{*}$ (D) and Fang Liu
}

\begin{abstract}
Background: Evidence-based medicine relies on current best evidence from the medical literature, the patient's history, and the clinician's own experience to provide the best care for patients. Systematic reviews and metaanalysis are considered the highest levels of evidence for informing clinical decisions. Recently, reports have shown an increase in the number but a decrease in quality of meta-analysis publications. We reviewed publication trends and determined the countries with the most journal articles and types of publications in PubMed from 1995 to 2015.

Methods: We examined journal entries in PubMed from 1995 to 2015 from top publishing countries for total number of publications and citations in core clinical journals and in specific publication types (systematic reviews, meta-analysis, randomized controlled trials).
\end{abstract}

Results: Yearly, only 30 countries generated $94.6 \%$ of all publications and $98.1 \%$ of core clinical journals worldwide. All publication types increased but with a significant increase in meta-analysis publications from China. Collaborative and co-authored papers among the 30 countries also showed an increasing trend.

Conclusion: The USA leads in all publication citations and specific publication types, except for meta-analysis where China publishes more. Collaborative publishing among international collaborators is also increasing.

Keywords: PubMed, Publication type, Meta-analysis, Systematic review, Collaborative publishing, Evidence-based medicine

\section{Background}

Recent best evidence from the literature and health care providers experience form the foundation of evidencebased medicine (EBM) [1]. In the hierarchy of evidence, randomized controlled trials, systematic reviews, and meta-analysis studies are at the highest levels in the evidence pyramid [2]. Meta-analysis and review articles are often the most highly cited publications [3]. Recently, the exponential increase in the number of meta-analysis studies has raised the issue of quality and reliability of metaanalysis publications [4-7]. The implications could be consequential because of the high value assigned to meta-analysis and systematic review studies in informing clinical decisions.

The publication type category in the MeSH translation table represents the article's type of material (ex: case report, clinical trial, editorial, guideline, meta-analysis,

\footnotetext{
* Correspondence: pfontelo@mail.nih.gov

National Library of Medicine, 8600 Rockville Pike, Bethesda, MD 20894, USA
}

etc.) [8]. The publication type in PubMed represents an article's "study design" and not the "type of material."

This paper is an attempt to review recent trends of some publication types in PubMed. It is not an assessment of the quality of journal articles themselves but rather a quantitative look at recent publication trends from top research countries worldwide.

\section{Methods}

PubMed searches were performed in December 2016 using the following limits: all publications sorted from top publishing countries from 1995 to 2015 and the following search strategies and publication types: metaanalysis, systematic reviews, clinical trials, and randomized controlled trials. A list of countries was created $(n=235)$ based on IPv4 Internet address allocations (https://en.wikipedia.org/wiki/List_of_countries_by_IPv4_address_allocation). The top publishing countries was generated from searches of all

(c) The Author(s). 2018 Open Access This article is distributed under the terms of the Creative Commons Attribution 4.0 International License (http://creativecommons.org/licenses/by/4.0/), which permits unrestricted use, distribution, and 
publications in PubMed for the year 2015. An example of a country search query for Germany is in Appendix 1. The number of publications in 2015 for each country was sorted, and the top 25 countries with the most publications were selected. Although the limit was initially set to the top 25 countries based on the total number of publications, five other countries that were not on the original list were found to be in the top 25 when specific publication types were analyzed. This brought the total highest publishing countries to 30 countries and regions. All journal articles from the 30 countries published between 1995 and 2015 in journals listed in National Library of Medicine (NLM)'s Abridged Index Medicus (AIM) or "Core Clinical" Journal Titles subset were also searched for publication types labeled as meta-analysis, systematic review, clinical trial, and randomized controlled trial. Examples of search filters for AIM journals are shown in Appendices 2, 3, and 4. The AIM or "Core Clinical" is a subset of MEDLINE [8] which currently includes about 119 journals. Publications from the 30 countries were reviewed in AIM subset $[9,10]$. Collaborative or co-authored publications were determined by searching for citations with combined affiliations between each of the top 5 countries and the 30 other countries on the list. In this paper, the term "citation" refers to the entry record of a publication in PubMed, not in its use in the reference section of a manuscript.

An expansion process for a country's name filter was performed to include the common expression in the affiliation field because of recent changes in PubMed (https:// www.nlm.nih.gov/pubs/techbull/so13/brief/so13_author_affiliations.html). For example, both "UK" and "United Kingdom" and "Russia" and "Russian Federation" were included in the affiliation filter to search for publications from the UK and Russia, respectively. Changes in indexing of affiliation information were instituted by the NLM in late December 2013 that required a modification of the search algorithm (https://www.nlm.nih.gov/pubs/techbull/ so13/brief/so13_author_affiliations.html). For the USA, the search algorithm was modified by adding all the names of the 50 states in the USA to compensate for this change in practice. Filter algorithms were continuously revised when "unexpected" results were encountered, such as, when entries from New Mexico state were included in results from Mexico, the country (Appendix 5).

A summary of search procedures for generating the data is as follows: Step 1: Find the countries with the most publications. Filters used in this step were affiliation filter and publication date filter. Step 2: Search for selected publication types from top 30 countries. These searches consisted of three filters: affiliation filter, publication date filter, and publication type filter. Step 3: Search for publications from top countries with selected publication types in core journals. Four search filters were used for this step: affiliation filter, publication date filter, publication type filter, and core journals filter. Step 4: Finally, find collaborative publications from the top publishing countries. Results were analyzed using Microsoft Excel. The search algorithms used in this study are shown in Appendices 1, 2, 3, 4, and 5.

\section{Results}

All data were from PubMed entries from January 1995 to December 2016. In Fig. 1, the total number of citations for the top 10 publishing countries from 1995 to 2015 are shown. The other 20 countries are not displayed because the lines were indistinguishable from each other. Research publications from the United States (USA) showed a steady rise and a doubling of publications in the 20-year review period. Starting around 2009,

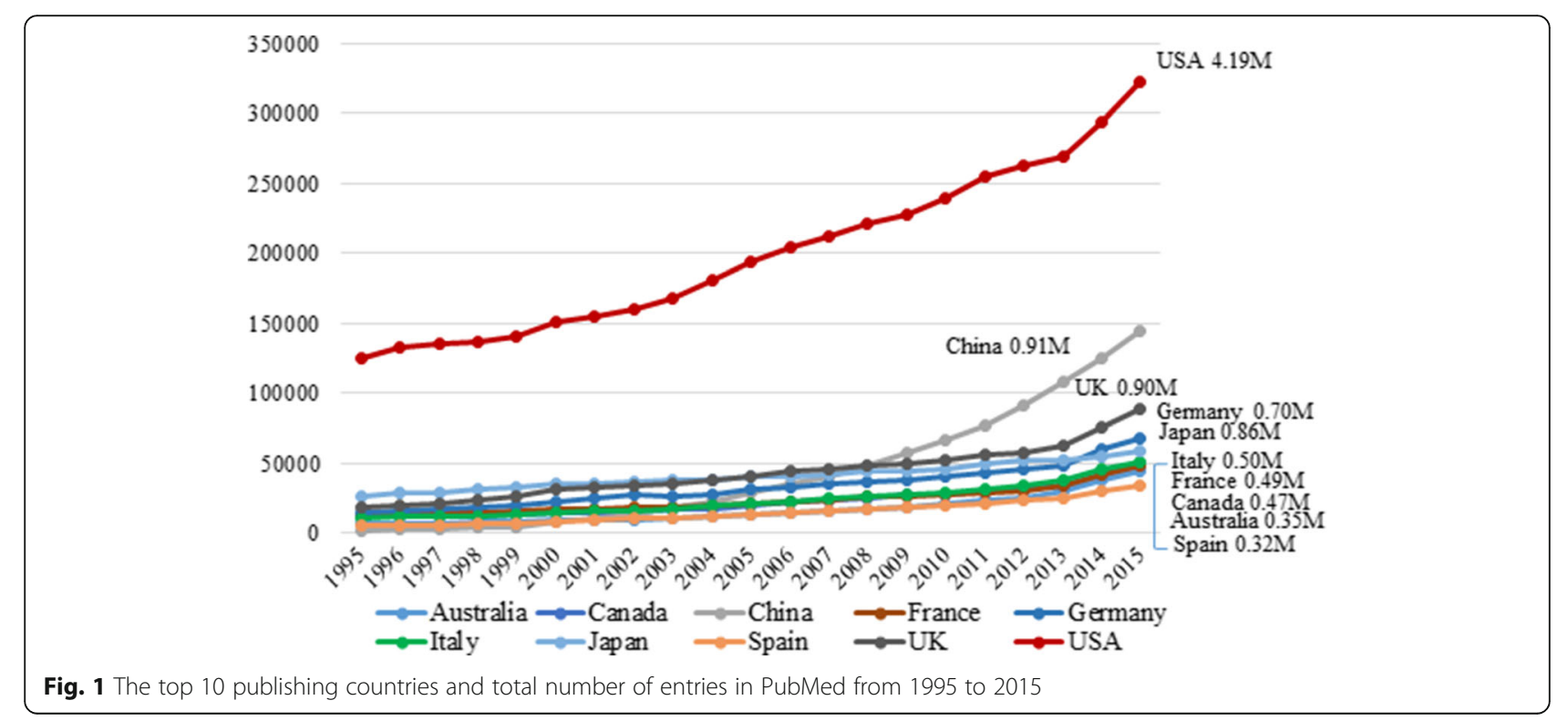


journal articles from China showed an increasing trend that parallels with the USA. Publications from other top publishing countries also showed an increasing trend but at a more gradual pace.

Table 1 shows data for all publications and the different publication types (systematic review, meta-analysis, clinical trials, and randomized clinical trial) from the top 30 publishing countries for 2015. The USA led in all publications, systematic reviews, clinical trials, and randomized clinical trials, but China published the most number of meta-analysis publications with the USA in second place.

Although we originally planned to determine the top 25 highest publishing countries only, we found that there were five other countries and regions that were represented in the top 25 when data for specific publication types were analyzed. This displaced some countries in the original list of top 25 countries in "All publication types." We subsequently decided to increase the total highest publishing countries and regions to 30 (Table 1). For systematic reviews, five other countries who were in the top 25 were Ireland, 18th; Greece, 21st; New Zealand, 22th; Norway, 23nd; and Hong Kong, 24th. Four countries who were not on the original 25 list but were in the top 25 for meta-analysis publications were Greece, 18th; Hong Kong, 22nd; Norway, 23rd; and Ireland, 24th. Norway was 21st in clinical trial publications and in randomized clinical

Table 1 Year 2015 country totals for all publications, systematic review, meta-analysis, clinical trials, and randomized clinical trials. Numbers inside " $\mathrm{"} \mathrm{indicate} \mathrm{country} \mathrm{rankings} \mathrm{for} \mathrm{each} \mathrm{category.} \mathrm{Countries} \mathrm{in} \mathrm{the} \mathrm{last} \mathrm{five} \mathrm{rows} \mathrm{(alphabetically} \mathrm{arranged)} \mathrm{were} \mathrm{not} \mathrm{in}$ the original top 25 most published countries but are in the top 25 in publication types (yellow box). Blue box indicates countries with most publications in the category.

\begin{tabular}{|c|c|c|c|c|c|}
\hline $\begin{array}{l}\text { Country } \\
\text { (Year } 2015 \text { only) }\end{array}$ & $\begin{array}{l}\text { All Publication } \\
\text { Types }\end{array}$ & $\begin{array}{l}\text { Systematic } \\
\text { Review }\end{array}$ & Meta-analysis & $\begin{array}{l}\text { Clinical } \\
\text { Trial }\end{array}$ & $\begin{array}{l}\text { Randomized } \\
\text { Clinical Trial }\end{array}$ \\
\hline Australia & [9] 44222 & [4] 1601 & [4] 1145 & [7] 1992 & [7] 1609 \\
\hline Austria & [24] 10700 & [26] 118 & {$[29] 123$} & [23] 526 & [23] 363 \\
\hline Belgium & [18] 15873 & {$[14] 300$} & {$[19] 220$} & [17] 877 & [17] 654 \\
\hline Brazil & [14] 26841 & [9] 575 & [9] 448 & [16] 1002 & [14] 767 \\
\hline Canada & [8] 47892 & [5] 1450 & [5] 1059 & [6] 2098 & [5] 1631 \\
\hline China & [2] 144853 & [3] 1821 & [1] 4659 & [4] 2605 & [4] 1801 \\
\hline Denmark & [21] 14973 & [13] 369 & {$[15] 325$} & [13] 1041 & [12] 820 \\
\hline France & [7] 48153 & [10] 499 & [10] 444 & [9] 1668 & [9] 1114 \\
\hline Germany & [4] 68360 & {$[8] 711$} & [8] 759 & [3] 2779 & [3] 1900 \\
\hline India & [10] 41408 & [17] 247 & {$[20] 201$} & [19] 619 & {$[18] 474$} \\
\hline Iran & [19] 15605 & {$[16] 272$} & {$[17] 267$} & [22] 535 & [19] 469 \\
\hline Israel & [23] 12984 & [25] 129 & {$[25] 146$} & {$[20] \quad 574$} & [22] 399 \\
\hline Italy & [6] 51212 & [7] 949 & [6] 952 & [8] 1899 & [8] 1236 \\
\hline Japan & [5] 58201 & [19] 212 & [13] 359 & [10] 1655 & [10] 926 \\
\hline Korea & [11] 36876 & [20] 209 & [12] 397 & [12] 1075 & [16] 750 \\
\hline Mexico & [25] 9499 & {$[30] 55$} & [30] 61 & [30] 255 & [29] 198 \\
\hline Netherlands & [13] 33303 & [6] 1025 & [7] 783 & [5] 2101 & [6] 1618 \\
\hline Poland & [22] 13640 & {$[28] 102$} & [28] 127 & [24] 521 & [24] 350 \\
\hline Spain & [12] 34559 & {$[11] 463$} & [11] 398 & [11] 1221 & [11] 894 \\
\hline Sweden & [16] 20020 & {$[15] 278$} & {$[16] 311$} & [15] 1036 & [15] 759 \\
\hline Switzerland & {$[15] 22075$} & [12] 403 & [14] 353 & [14] 1038 & [13] 787 \\
\hline Taiwan & [20] 15049 & [27] 113 & [21] 173 & [25] 395 & [27] 252 \\
\hline Turkey & [17] 19963 & [31] 55 & [31] 55 & [18] 671 & {$[20] 466$} \\
\hline UK & [3] 88871 & [2] 3030 & [3] 2050 & [2] 3601 & [2] 2839 \\
\hline USA & [1] 323047 & [1] 3654 & [2] 3256 & [1] 11095 & [1] 7953 \\
\hline Hong Kong & [30] 6941 & [24] 130 & [22] 173 & [29] 259 & {$[28] 208$} \\
\hline Greece & {$[28] 7592$} & [21] 194 & {$[18] 244$} & {$[28] \quad 265$} & {$[30] 189$} \\
\hline Ireland & [29] 6971 & {$[18] 215$} & [24] 149 & [31] 221 & {$[31] 184$} \\
\hline New Zealand & [31] 6647 & [22] 184 & {$[27] 142$} & [27] 361 & [25] 311 \\
\hline Norway & [26] 8736 & [23] 149 & [23] 170 & [21] 548 & [21] 426 \\
\hline
\end{tabular}


trials, while New Zealand was in 25th place for randomized clinical trials.

For all publication types in 2015, the USA had more than twice as many publications as China $(323,047$ vs 144,850), which was second highest (Table 1). The United Kingdom (UK) was third highest at 88,271 or $27.3 \%$ of the US total. In 2015, the top 10 countries were (from highest to lowest) US, China, UK, Germany, Japan, Italy, France, Canada, Australia, and Spain.

The Abridged Index Medicus (AIM) or "Core Clinical," a subset of MEDLINE, [9] which currently lists about 119 journals, contains some of the most highly read and highly cited clinical journals [10]. We reviewed the publications from the 30 countries in AIM subset and found that from 1995 to 2015 (Table 2), the average yearly output from the 30 top producing countries was $93.9 \%$ for all publication types and $98.1 \%$ for core journals (total number of countries $=235$ ). The average varied only slightly from year-to-year in the 20-year review period.

A review of meta-analysis and systematic review publications from the top 10 publishing countries are shown in Fig. 2. The results are similar to that seen in Table 1, where the USA published the most articles in all publications. For China, the rapid growth in meta-analysis publications started in 2009, and eventually surpassing the USA in 2011. Although at the end of 2015 the USA still had more meta-analysis publications than China overall $(16,581$ vs 15,345$)$, it was already $93 \%$ that of the USA and growing at a steeper slope. Compared to the USA, the total percentage of China's output for total publications, systematic reviews, clinical trials, and randomized controlled trials were much lower-22\%, 26\%, $14 \%$, and $15 \%$, respectively.

Since "Systematic Review" is not a publication type filter in PubMed, but rather, a subset filter, the search algorithm was modified by including the title and "text word" combination to find articles of that type. The modified filter for systematic reviews was "(systematic review [tw] OR systematic review [tiab] OR meta synthesis [ti] OR cochrane database syst rev [ta] OR systematic literature review [ti] OR pooling project [tw] OR umbrella review [tw])" . Figure 2 shows that the USA leads in systematic reviews that is maintained throughout the 20-year period.

Co-authored publications with the US collaborators account for the highest percentage among the top 30

Table 2 Total publications from 30 countries compared to all countries $(n=235)$. Yearly average was $93.9 \%$ and $98.1 \%$ for all publication types and core clinical journals

\begin{tabular}{|c|c|c|c|c|c|c|}
\hline \multirow[t]{2}{*}{ Year } & \multicolumn{3}{|l|}{ All Pub types } & \multicolumn{3}{|l|}{ Core journals } \\
\hline & All countries $(n=235)$ & Top 30 only & $\% 30 / 235$ & All countries $(n=235)$ & Top 30 only & $\% 30 / 235$ \\
\hline 1995 & 291,806 & 277,457 & 95.1 & 30,998 & 30,110 & 97.1 \\
\hline 1996 & 313,995 & 298,289 & 95.0 & 33,112 & 32,197 & 97.2 \\
\hline 1997 & 324,191 & 307,440 & 94.8 & 34,259 & 33,267 & 97.1 \\
\hline 1998 & 341,228 & 322,652 & 94.6 & 34,814 & 33,839 & 97.2 \\
\hline 1999 & 358,148 & 338,015 & 94.4 & 35,907 & 34,818 & 97.0 \\
\hline 2000 & 399,072 & 375,098 & 94.0 & 36,334 & 35,287 & 97.1 \\
\hline 2001 & 421,876 & 396,344 & 93.9 & 36,359 & 35,383 & 97.3 \\
\hline 2002 & 444,372 & 417,469 & 93.9 & 37,612 & 36,647 & 97.4 \\
\hline 2003 & 473,301 & 443,748 & 93.8 & 38,963 & 37,906 & 97.3 \\
\hline 2004 & 514,557 & 482,641 & 93.8 & 40,206 & 38,710 & 96.3 \\
\hline 2005 & 570,137 & 534,627 & 93.8 & 41,012 & 39,248 & 95.7 \\
\hline 2006 & 614,911 & 576,849 & 93.8 & 40,137 & 38,987 & 97.1 \\
\hline 2007 & 655,660 & 614,277 & 93.7 & 40,446 & 39,338 & 97.3 \\
\hline 2008 & 702,786 & 657,358 & 93.5 & 40,669 & 39,593 & 97.4 \\
\hline 2009 & 741,151 & 691,626 & 93.3 & 40,946 & 39,829 & 97.3 \\
\hline 2010 & 799,670 & 744,345 & 93.1 & 41,423 & 40,277 & 97.2 \\
\hline 2011 & 872,932 & 811,309 & 92.9 & 42,351 & 41,317 & 97.6 \\
\hline 2012 & 937,430 & 870,338 & 92.8 & 41,330 & 40,282 & 97.5 \\
\hline 2013 & 977,245 & 909,156 & 93.0 & 41,529 & 40,724 & 98.1 \\
\hline 2014 & $1,006,344$ & 945,443 & 93.9 & 44,457 & 43,857 & 98.7 \\
\hline 2015 & $1,064,266$ & $1,006,618$ & 94.6 & 48,141 & 47,245 & 98.1 \\
\hline
\end{tabular}




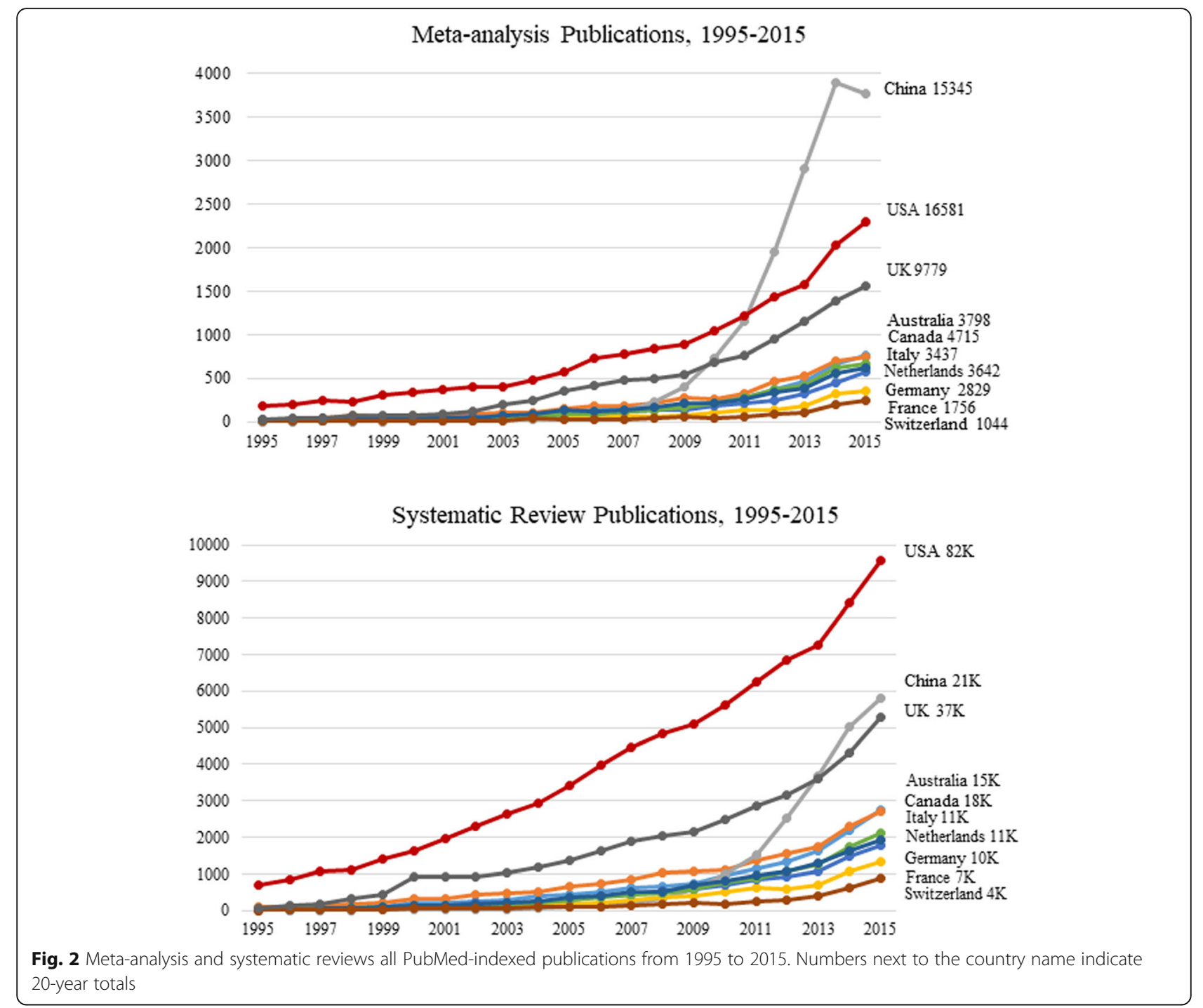

countries (Table 3 ). In 2015, the USA published 89,060 papers in collaboration with other countries, which is $27.6 \%$ of its total publication output $(323,047)$. Collaborators from China were co-authors in 19.8\% (highest) of US total publications, followed by $16.0 \%$ from the UK, and $12.9 \%$ from Canada. In 2015, China published 34,089 co-authored publications (23.5\% of total publications), with $51.7 \%$ co-authored with US scientists, $14.4 \%$ from Hong Kong, and 9.3\% from Taiwan. From 1995 to 2015, there was a mix of decreases and increases in cross country co-authorship; however, the absolute numbers of collaborative publications between the top 5 countries and 30 other countries on the list increased from 2093 in 1995 to 357,746 in 2015. For the other top 4 countries (Table 3), the most co-authored papers were also with the USA. The overall number of co-authored publications for the 30 top research countries, from 1995 to 2015 , was 780,521.
Prior to October 2013, PubMed only indexed the first author's affiliation. We wanted to determine how the change in policy of listing the affiliation of all authors made a difference, by comparing collaborative publication data for 10 years (2006 to 2015). Figure 3 illustrates the rapid increase in collaborative publications after 2013 as a result of this policy change. Although it can be attributed to the policy change, the increasing trend during the consecutive years may be real, stemming from increased collaborations between institutions internationally. Figure 3 also shows that even before 2013, there were already papers with multiple affiliations in PubMed entries, about $8 \%$ for China and $4 \%$ for the UK.

\section{Discussion}

Recent reports of the rapid increase in meta-analysis publications from China prompted this study [4-7]. Our 
Table 3 Collaborative publications between the top 5 countries with the 30 other highly published countries for 2015 . Yellow boxes indicate the country with the most co-authored papers

\begin{tabular}{|c|c|c|c|c|c|}
\hline Year 2015 & China & Germany & Japan & UK & USA \\
\hline Australia & $7.3 \%$ & $6.9 \%$ & $8.1 \%$ & $12.6 \%$ & $7.5 \%$ \\
\hline Austria & $0.9 \%$ & $9.1 \%$ & $2.6 \%$ & $3.3 \%$ & $2.1 \%$ \\
\hline Belgium & $1.3 \%$ & $6.8 \%$ & $3.3 \%$ & $6.0 \%$ & $3.1 \%$ \\
\hline Brazil & $1.1 \%$ & $3.2 \%$ & $2.9 \%$ & $3.1 \%$ & $4.3 \%$ \\
\hline Canada & $6.5 \%$ & $8.0 \%$ & $8.1 \%$ & $9.3 \%$ & $12.9 \%$ \\
\hline China & & $6.6 \%$ & $21.7 \%$ & $6.9 \%$ & $19.8 \%$ \\
\hline Denmark & $1.5 \%$ & $5.7 \%$ & $2.8 \%$ & $5.9 \%$ & $3.0 \%$ \\
\hline France & $3.3 \%$ & $14.2 \%$ & $9.0 \%$ & $12.9 \%$ & $7.6 \%$ \\
\hline Germany & $6.0 \%$ & & $13.5 \%$ & $19.3 \%$ & $12.0 \%$ \\
\hline India & $1.4 \%$ & $1.9 \%$ & $3.6 \%$ & $2.9 \%$ & $2.9 \%$ \\
\hline Iran & $0.4 \%$ & $0.9 \%$ & $0.7 \%$ & $1.0 \%$ & $0.9 \%$ \\
\hline Israel & $1.1 \%$ & $3.3 \%$ & $2.3 \%$ & $2.1 \%$ & $5.7 \%$ \\
\hline Italy & $2.6 \%$ & $13.2 \%$ & $7.2 \%$ & $12.6 \%$ & $7.8 \%$ \\
\hline Japan & $7.4 \%$ & $5.0 \%$ & & $4.1 \%$ & $6.0 \%$ \\
\hline Korea & $3.2 \%$ & $2.0 \%$ & $7.8 \%$ & $1.5 \%$ & $5.0 \%$ \\
\hline Mexico & $1.0 \%$ & $1.3 \%$ & $1.6 \%$ & $1.2 \%$ & $4.4 \%$ \\
\hline Netherlands & $2.5 \%$ & $13.7 \%$ & $5.2 \%$ & $12.3 \%$ & $6.4 \%$ \\
\hline Poland & $0.8 \%$ & $4.0 \%$ & $2.0 \%$ & $2.7 \%$ & $1.6 \%$ \\
\hline Spain & $1.7 \%$ & $9.9 \%$ & $5.2 \%$ & $9.5 \%$ & $5.5 \%$ \\
\hline Sweden & $2.3 \%$ & $7.1 \%$ & $4.5 \%$ & $7.1 \%$ & $4.0 \%$ \\
\hline Switzerland & $1.9 \%$ & $13.5 \%$ & $4.9 \%$ & $8.0 \%$ & $5.1 \%$ \\
\hline Taiwan & $9.3 \%$ & $0.9 \%$ & $4.2 \%$ & $1.0 \%$ & $2.2 \%$ \\
\hline Turkey & $0.6 \%$ & $1.8 \%$ & $1.5 \%$ & $1.3 \%$ & $1.4 \%$ \\
\hline UK & $8.4 \%$ & $25.5 \%$ & $14.6 \%$ & & $16.0 \%$ \\
\hline USA & $51.7 \%$ & $34.0 \%$ & $46.0 \%$ & $34.4 \%$ & \\
\hline Greece & $0.6 \%$ & $2.8 \%$ & $1.5 \%$ & $3.0 \%$ & $1.3 \%$ \\
\hline Hong Kong & $14.4 \%$ & $0.7 \%$ & $2.2 \%$ & $1.3 \%$ & $1.3 \%$ \\
\hline Ireland & $0.6 \%$ & $2.0 \%$ & $1.1 \%$ & $4.6 \%$ & $1.2 \%$ \\
\hline New Zealand & $0.8 \%$ & $1.1 \%$ & $1.2 \%$ & $2.2 \%$ & $1.2 \%$ \\
\hline Norway & $0.8 \%$ & $3.1 \%$ & $1.9 \%$ & $3.5 \%$ & $1.7 \%$ \\
\hline $\begin{array}{l}2015 \text { Total co- } \\
\text { authored citations }\end{array}$ & 34129 & 31372 & 11646 & 41380 & 89132 \\
\hline
\end{tabular}

review seemed to confirm this trend. Although the majority of total journal articles were still published by researchers in the USA, data from 1995 to 2015 showed that China was almost equal in number to that of the USA in meta-analysis publications. China's meta-analysis publications are at a steeper slope than any other country since it started in 2009 (Fig. 2) and has overtaken all countries in the top 10 category. In this review, we also found an increase in collaborative publishing among the top publishing countries.

Some reports cite evidence-based medicine as the stimulus for the rapid rise in the number of meta-analysis publications in China [4] and to the pressures of academia [6]. Ioannidis attributes the recent increase to contracting companies "operating in the domain of evidence synthesis" [5]. The tools for doing a meta-analysis and systematic reviews are widely accessible. However, this study did not show an increase in systematic reviews.

International collaboration improves the quality of research for all partners although it has some challenges as well [11]. The growth of collaborative research with China and other countries has been reported [11]. Publications in international journals from all countries have increased over the years as evidenced by total publications (Table 3 and Fig. 3). An even more positive development is the increased international collaborations between the top publishing countries (Fig. 3). In 2015 (Table 3), co-published papers between China and the USA accounted for $51.7 \%$ of China's co-authored 


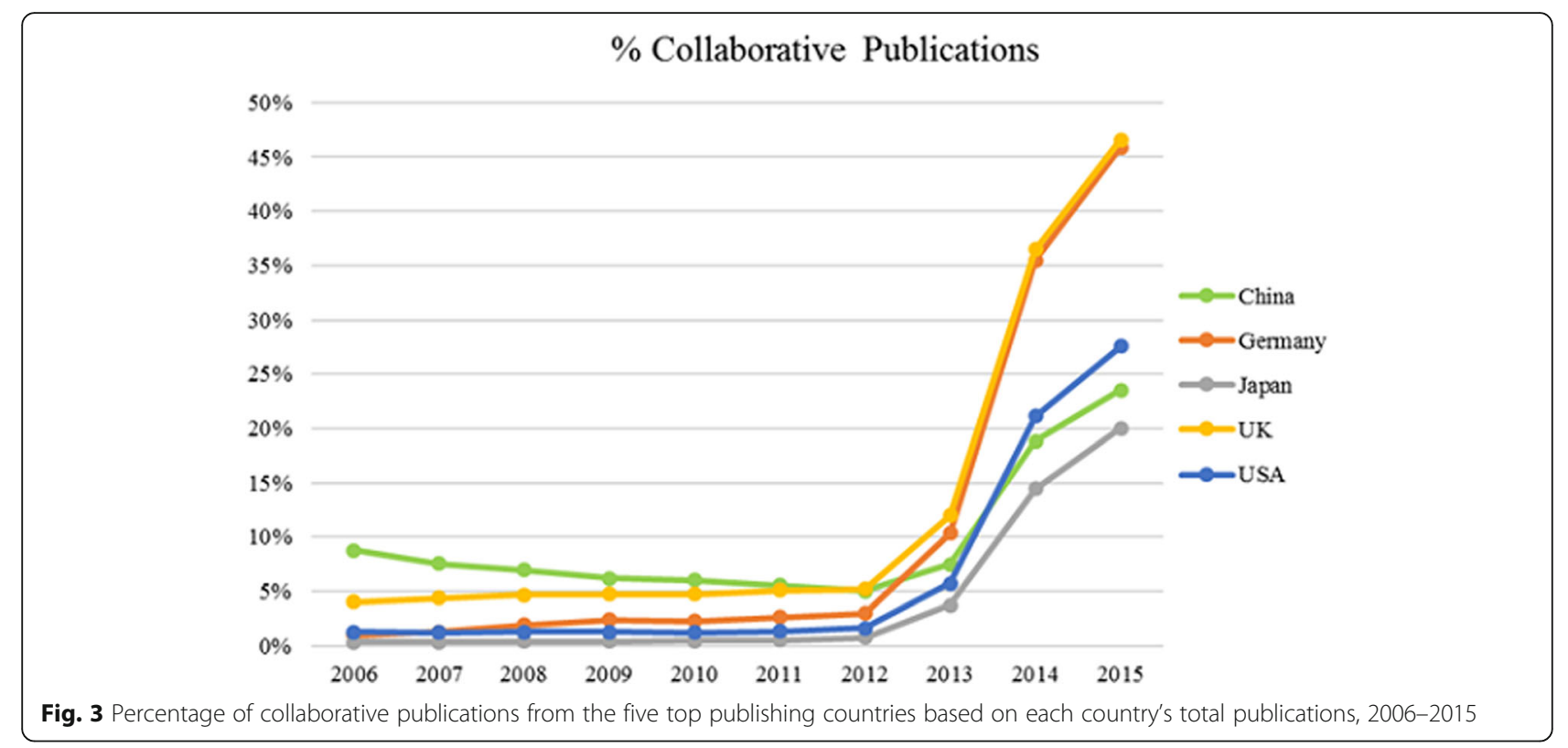

publications. Collaborations with other countries and regions were high as well (Hong Kong 14.4\%, Taiwan 9.3\%, Australia 7.3\%, Japan 7.4\%, Canada 6.5\%, Germany 6\%). In $2015,27.6 \%$ of total US' publications (34129) were collaborative publications. The most co-authored journal papers were with China, 19.8\%; the UK, $16 \%$; Canada, 12.2\%; and Germany, 12\%. The lack of data for all author affiliations before 2013 makes the trend of earlier international collaborative publications unclear. But from the first authors' affiliations before 2013 (Fig. 3), we can infer that scientists working collaboratively have increased over the years.

Although we attempted to include all publications from the 235 countries with citations in PubMed, we may have missed some publications because some co-authors' affiliations may not have been indexed in PubMed before 2013. Other reasons may include NLM indexing affiliations of authors only if provided by publishers in their XML submissions; association of authors with multiple institutions and not listing all affiliations; and discontinued editing of author affiliation field in MEDLINE/PubMed citations. In the past, NLM policy was to indicate the affiliation for the first author only and edited the field by adding "USA" (https:// www.nlm.nih.gov/pubs/techbull/so13/brief/so13_author_affiliations.html). For example, many publications from the USA only list the states or even only the academic institution or the organization where they originated. After 2013, PubMed discontinued adding "USA" in the affiliation field. In our search algorithm, we added all the states in the USA to compensate for this. Some publications from China, Russia, or the Russian Federation that may have listed only their academic affiliations or cities would have missed their country affiliation. Unlike the authors in the USA, we cannot compensate by adding the names of all the states for China and Russia. However, a random search of over 200 articles from Russia and China all showed their countries in the affiliation field. It is unlikely, but this is still a possible limitation of the study.

Wilczynski and Haynes [12], analyzing the consistency and accuracy of several search strategies, found that using only single terms yielded low sensitivities-76.5\% for "Review.pt" and 19\% for "Meta analysis.pt." In our search algorithms, we tried to include filters (Appendices 2, 3, and 4), similar to those used by Shojania and Bero [13] that yielded sensitivities between 93 and 97\% and would identify publications that are systematic reviews and meta-analysis. However, there is no assurance that we have found all of these articles. This may be a limitation.

We found in this 20-year review of publications that only 30 countries (out of 235 total reviewed) are responsible for an average of $93.9 \%$ of all publications in PubMed. What might explain the few numbers of countries responsible for a majority of the world's literature? It is likely a consequence of country priorities, lower levels of funding, and the high cost of doing research, although labor costs may be lower [14]. Biomedical research is often not a top priority in developing countries. However, although the research output of developing counties may be relatively low, many important medical and public health interventions were developed in developing countries, such as life-saving interventions like oral rehydration therapy for diarrhea and vitamin A to reduce infant mortality [15]. Moreover, 
collaborative research may be indexed as publications from funding agencies or collaborators in developed countries [11]. Other countries may also have fewer research and academic institutions. Developing countries can make important contributions to the medical literature, especially in the area of infectious diseases, and increasingly, non-communicable chronic diseases. Top research countries and research funding agencies may need to collaborate more with other countries. Some of this may be occurring through the internationalization of clinical trials that are now done worldwide and increased student and fellowship training [11].

We had also considered whether the rapid increase of publications might be explained by so-called predatory journals-low-quality journals with little or no peer review, which promise rapid publication but exist solely for profit [16]. However, we do not believe that these journals are responsible because this evaluation is based only in publications indexed in PubMed. Some data indicate that a few of these types of journals are indexed in PubMed. Moreover, Shen and Bjork also reported that "the problem of predatory open access seems highly contained to just a few countries, where the academic evaluation practices strongly favor international publication, but without further quality checks" [17].

\section{Conclusion}

This study showed the continuing increase in research publications globally. The USA still leads the world in all publications and specific publication types except in meta-analysis where recently China now publishes more. Increasing collaborations and authorships among countries with the USA, China, and other top publishing countries is also increasing.

\section{Appendix 1}

Example of a filter for searching for country publications for Germany from 1995 to 2015

"Germany[affiliation] AND 2015/01/01 [PDAT] : 2015/12/ 31 [PDAT]"

\section{Appendix 2}

Filters for searching for systematic review and meta-analysis from 1995 to 2015 for China

systematic review [ti] AND (meta-analysis [pt] OR meta-analysis [ti] OR systematic review [tw] OR systematic review [tiab] OR meta synthesis [ti] OR meta-analy*[ti] OR cochrane database syst rev [ta] OR systematic literature review [ti] OR pooling project [tw] OR umbrella review [tw] )AND “1995/01/01"[PDAT] : “2015/12/31"[PDAT] AND China[affiliation]

\section{Appendix 3}

Filters to search for systematic reviews only from 1995 to 2015 replace China with name of country

(systematic review [tw] OR systematic review [tiab] OR meta synthesis [ti] OR cochrane database syst rev [ta] OR systematic literature review [ti] OR pooling project [tw] OR umbrella review [tw] )AND “1995/01/ 01”[PDAT] : “2015/12/31”[PDAT] AND China[affiliation]

\section{Appendix 4}

Filters to search for meta-analysis only from 1995 to 2015 for China

(meta-analysis [pt] OR meta-analysis [ti] OR meta synthesis [ti] OR meta-analy*[ti] ) AND “1995/01/01"[PDAT] : “2015/12/31”[PDAT] AND China[affiliation]

\section{Appendix 5}

Filters to search for meta-analysis only the Mexico (country) only, not New Mexico state

(meta-analysis [pt] OR meta-analysis [ti] OR meta synthesis [ti] OR meta-analy*[ti] ) AND “1995/01/01"[PDAT] : “2015/12/31"[PDAT] AND mexico[affiliation] NOT new mexico[affiliation]

\section{Funding}

This research was supported by the Intramural Research Program of the National Institutes of Health, National Library of Medicine, and Lister Hill National Center for Biomedical Communications.

\section{Availability of data and materials}

The datasets generated and/or analyzed during the current study are available from the corresponding author on reasonable request.

\section{Disclaimer}

The views and opinions of the authors expressed herein do not necessarily state or reflect those of the National Library of Medicine, National Institutes of Health, or the US Department of Health and Human Services.

\section{Authors' contributions}

PF conceived of the study and study design, participated in the data analysis, and drafted the manuscript. FL assisted in the study design, developed the algorithms used in the study, assisted in the data analysis, and drafted the manuscript. All authors read and approved the final manuscript.

Ethics approval and consent to participate

Not applicable

Consent for publication

Not applicable

Competing interests

The authors declare that they have no competing interests.

\section{Publisher's Note}

Springer Nature remains neutral with regard to jurisdictional claims in published maps and institutional affiliations.

Received: 17 April 2018 Accepted: 17 September 2018 Published online: 27 September 2018

\section{References}

1. Rosenberg WM, Gray JA, Haynes RB, Richardson WS, Sackett DL. Evidence based medicine: what it is and what it isn't. BMJ. 1996; 312(7023):71-2. 
2. Petrisor BA, Keating J, Schemitsch E. Grading the evidence: levels of evidence and grades of recommendation. Injury. 2006;37(4):321-7.

3. Patsopoulos NA, Analatos AA, loannidis JP. Relative citation impact of various study designs in the health sciences. JAMA. 2005; 293(19):2362-6.

4. Ye XF, Yu DH, He J. The rise in meta-analyses from China. Epidemiology 2013; 24(2):335-6.

5. Ioannidis JP. The mass production of redundant, misleading, and conflicted systematic reviews and meta-analyses. Milbank Q. 2016;94(3):485-514.

6. Yang ZP, Ye XF, Fan DM. Meta-analysis is victim to Chinese academic and educational systems. J Formos Med Assoc. 2013; 112(5):235-6.

7. Ioannidis JP, Chang CQ, Lam TK, Schully SD, Khoury MJ. The geometric increase in meta-analyses from China in the genomic era. PLoS One. 2013; 8(6):e65602.

8. PubMed Help [Internet]. Bethesda (MD): National Center for Biotechnology Information (US); 2005-. PubMed Help. [Updated 2016 Aug 30]. Available from: https://www.ncbi.n/m.nih.gov/books/NBK3827/

9. Abridged Index Medicus (AIM) or "Core Clinical" Journal Titles. https://www. nlm.nih.gov/bsd/aim.html. Accessed 5 Sept 2018.

10. Hoogendam A, et al. Evaluation of PubMed filters used for evidencebased searching: validation using relative recall. J Med Libr Assoc. 2009; 97(3):186-93.

11. Wagner CS, Park HW, Leydesdorff $L$. The continuing growth of global cooperation networks in research: a conundrum for national governments. PLoS One. 2015;10(7):e0131816. https://doi.org/10.1371/journal.pone.0131816.

12. Wilczynski NL, Haynes RB. Consistency and accuracy of indexing systematic review articles and meta-analyses in MEDLINE. Health Inf Libr J. 2009; 26(3): 203-10.

13. Shojania KG, Bero LA. Taking advantage of the explosion of systematic reviews: an efficient MEDLINE search strategy. Eff Clin Pract. 4, 4:157-62.

14. The cost of research in developing countries. van Helden P. EMBO Rep; 2012 May; 13(5):395. EMBO Rep (2012) 13, 395; published online 3 April 2012; doi:https://doi.org/10.1038/embor.2012.43

15. National Research Council. The fundamental role of science and technology in international development: an imperative for the U.S. Agency for international development. Washington, DC: The National Academies Press. Summary; 2006. p. 1. https://doi.org/10.17226/11583.

16. Moher D, Moher E. Stop predatory publishers now: act collaboratively. Ann Intern Med. 2016; 164(9):616-7.

17. Shen C, Bjork BC. 'Predatory' open access: a longitudinal study of article volumes and market characteristics. BMC Med. 2015;13:230.

Ready to submit your research? Choose BMC and benefit from:

- fast, convenient online submission

- thorough peer review by experienced researchers in your field

- rapid publication on acceptance

- support for research data, including large and complex data types

- gold Open Access which fosters wider collaboration and increased citations

- maximum visibility for your research: over $100 \mathrm{M}$ website views per year

At $\mathrm{BMC}$, research is always in progress.

Learn more biomedcentral.com/submissions 